ISSN 1808-3765

\title{
CLASSIFICAÇÃO CLIMÁTICA PARA OS MUNICÍPIOS DE BOTUCATU E SÃO MANUEL, SP
}

\author{
Antonio Ribeiro da Cunha; Dinival Martins \\ ${ }^{1}$ Departamento Recursos Naturais - Ciências Ambientais, Faculdade de Ciências Agronômicas, Universidade \\ Estadual Paulista, Botucatu, SP, arcunha@fca.unesp.br
}

\section{RESUMO}

A classificação climática procura definir os limites geográficos dos diferentes tipos de clima que ocorrem em todo mundo, sendo considerado um estudo básico para áreas afins. Este trabalho teve como objetivo classificar climaticamente os municípios Botucatu (Fazenda Experimental do Lageado) e de São Manuel (Fazenda Experimental de São Manuel) ambas da Faculdade de Ciências Agronômicas - UNESP, Campus de Botucatu, SP. Para tanto, utilizouse das metodologias de Köppen e de Thornthwaite em dados normais de temperatura do ar e precipitação pluviométrica no período de 36 anos (1971 a 2006). Os municípios de Botucatu e de São Manuel tiveram a mesma classificação climática pelo método de Köppen, como sendo Cfa, clima temperado quente (mesotérmico) úmido, e a temperatura média do mês mais quente é superior a $22{ }^{\circ} \mathrm{C}$. Pela classificação de Thornthwaite houve uma pequena diferença em função do índice de umidade, caracterizando como $\mathbf{B}_{2} \mathbf{r} \mathbf{B}^{\prime}{ }_{3} \mathbf{a}^{\prime}$ (clima úmido com pequena deficiência hídrica - abril, julho e agosto, mesotérmico, com evapotranspiração potencial anual de $945,15 \mathrm{~mm}$ e concentração da evapotranspiração potencial no verão igual a $33 \%$ ) o município de Botucatu, e como $\mathbf{B}_{1} \mathbf{r} \mathbf{B}{ }_{3} \mathbf{a}$ ' (clima úmido com pequena deficiência hídrica abril, julho e agosto, mesotérmico, com evapotranspiração potencial anual de 994,21 mm e concentração da evapotranspiração potencial no verão igual a 33\%) o município de São Manuel.

UNITERMOS: temperatura do ar, precipitação, evapotranspiração, método de Köppen, método de Thornthwaite.

\section{CUNHA, A. R.; MARTINS, D. CLIMATIC CLASSIFICATION FOR THE DISTRICTS OF BOTUCATU AND SÃO MANUEL, SP}

\section{ABSTRACT}

Climatic classification defines the geographical limits of different climate types all over the world, and it is considered essential to study similar areas. This work updates the climatic classification of the municipal districts of Botucatu and of São Manuel, State of Sao Paulo, where the experimental farms of the Schools of Agronomical Sciences - UNESP, Campus of Botucatu, State of São Paulo, are located. Köppen's and Thornthwaite's methods were used for the air temperature and precipitation data in a 36-year period (from 1971 to 2006). For both municipal districts of Botucatu and São Manuel, the climate was characterized as being $\mathbf{C f a}$, hot climate with rains in the summer and drought in the winter, and the average temperature in the hottest month is above $22^{\circ} \mathrm{C}$. According to Thornthwaite's classification, there was a small difference due to the humidity index, characterized as 
$\mathbf{B}_{2} \mathbf{r B}{ }_{3} \mathbf{a}^{\prime}$ (humid climate with small hydro deficiency - April, July and August, with annual potential evapotranspiration of $945.15 \mathrm{~mm}$ and concentration of the potential evapotranspiration in the summer of $33 \%$ ) in the district of Botucatu, and as $\mathbf{B}_{1} \mathbf{r} \mathbf{B}^{\prime}{ }_{3} \mathbf{a}^{\prime}$ (humid climate with small hidric deficiency - April, July and August, with annual potential evapotranspiration of $994.21 \mathrm{~mm}$ and concentration of the potential evapotranspiration in the summer of 33\%)in the district of São Manuel.

KEY WORDS: air temperature, precipitation, evapotranspiration, Köppen method, Thornthwaite method.

\section{INTRODUÇÃO}

A classificação climática tem como objetivo a definição dos limites geográficos dos diferentes tipos de clima que ocorrem em todo mundo, sendo considerado um estudo básico para áreas afins. Ela apresenta três objetivos que se inter-relacionam: ordenar grande quantidade de informações, facilitar a rápida recuperação e facilitar a comunicação. Para isso, faz-se a descrição e mapeamento das regiões climáticas, necessitando-se identificá-las e classificá-las em diferentes tipos.

O número de elementos que devem ser combinados em uma determinada classificação climática depende do propósito a que ela se destina. Por exemplo, uma classificação climática baseada em temperaturas críticas e limites de umidade é satisfatória para o crescimento de certas plantas ou para organismos animais, mas não para fins de previsão de tempo. Sendo assim, é importante identificar o fim a que se destina a classificação.

Segundo a Organização Meteorológica Mundial, o clima não se mostra senão após um estudo metódico de um longo período, um mínimo de 30 anos, sendo de primordial importância a origem e qualidade dos dados analisados para a confiabilidade da classificação. Para tanto, dois métodos de classificação são amplamente utilizados, Köppen e o de Thornthwaite, sendo o primeiro função de dados normais de temperatura e precipitação, enquanto o segundo, além dos citados, incorpora também a evapotranspiração potencial.

A classificação climática de Köppen é baseada em valores médios anuais e mensais de temperatura e precipitação, e a vegetação nativa é utilizada para determinar os limites climatológicos de sua classificação, que apresenta cinco grandes climas representados pelas letras A, B, C, D e E. Cada clima é caracterizado mais detalhadamente e recebe duas ou três letras minúsculas do alfabeto. É uma classificação incontestável e usada há mais de 80 anos, possuindo um caráter didático, e permitindo adaptá-la para diferentes níveis, sendo ao mesmo tempo, simples e detalhada (Vianello \& Alves, 2000). A facilidade de composição de letras contribui para uma maior difusão desta classificação em todos os setores interessados: arquitetura, agronomia, botânica, engenharia civil, hidrologia, geologia e geografia.

No Brasil, a utilização da classificação de Köppen é comum pelo Instituto de Geografia e Estatística (IBGE) e outros órgãos estaduais ou estatais. Alguns autores já se utilizaram da metodologia de Köppen para a classificação climática de alguns locais, tais como: Deffune et al. (1994) que classificaram o clima de Maringá (PR) como sendo Cw'h, Figueiredo \& Sugahara (1997) que classificaram o clima de Bauru (SP) como sendo Cfa, Vianello \& Alves (2000) classificaram o clima de Viçosa (MG) como sendo Cwa, o mesmo clima da região de Lavras (MG) segundo Dantas et al. (2007).

A classificação de Thornthwaite leva em conta quatro letras. A primeira se refere ao índice de umidade, a segunda indica os traços dominantes da variação sazonal de umidade 
efetiva, a terceira aponta a eficiência térmica e a quarta representa a concentração da eficiência térmica no verão em função da evapotranspiração potencial (Thornthwaite, 1948). A classificação de Thornthwaite detecta pequenas variações espaciais climáticas com mais eficência do que a de Köppen.

Segundo a classificação de Thornthwaite, Nogueira \& Lima (1989) classificaram os municípios de Pacoti e Guaramiranga, CE, como $\mathbf{B}_{2} \mathbf{r} \mathbf{B}{ }_{4} \mathbf{a}^{\prime}$ e $\mathbf{B}_{4} \mathbf{r} \mathbf{B}{ }_{3}{ }_{3} \mathbf{a}$, sendo a altitude o parâmetro que exerce grande influência neste resultado. Santana et al. (2004) encontraram DdA'a' para o município de Serra Negra do Norte, RN, uma condição semi-árida nordestina. Dantas et al. (2007) para a região de Lavras, encontraram como sendo $\mathbf{B}_{2} \mathbf{r} \mathbf{B}_{3}{ }_{3} \mathbf{a}$ '.

Jurca (2005) utilizou-se das duas classificações analisando dados mensais de temperatura e totais mensais de precipitação, no período de 1950 a 1999, para o estado de São Paulo e sul do Brasil, e constatou que a classificação de Thornthwaite detectou as pequenas variações climáticas com mais eficiência que a de Köppen.

O objetivo deste trabalho foi classificar climaticamente os municípios de Botucatu (Fazenda Lageado) e de São Manuel (Fazenda Experimental de São Manuel) ambas da Faculdade de Ciências Agronômicas - UNESP, Campus de Botucatu, através das metodologias de Köppen e de Thornthwaite, amplamente utilizadas, para aplicações em áreas afins da Universidade e por setores de interesse.

\section{MATERIAL E MÉTODOS}

Através das classificações climáticas de Köppen e de Thornthwaite, e utilizando-se de dados normais de temperatura do ar e precipitação pluviométrica medidos em estação meteorológica do Departamento de Recursos Naturais - Setor Ciências Ambientais, na Fazenda Experimental Lageado da Faculdade de Ciências Agronômicas - UNESP, Campus de Botucatu, SP (22 $51^{\prime} \mathrm{S}$ de latitude, $48^{\circ} 26^{\prime} \mathrm{W}$ de longitude, e $786 \mathrm{~m}$ de altitude), e na Fazenda Experimental de São Manuel - UNESP, Campus de Botucatu (22 $46^{\circ}$ ' S de latitude, $48^{\circ} 34^{\prime} \mathrm{W}$ de longitude, e $740 \mathrm{~m}$ de altitude), determinou-se o tipo climático para os municípios de Botucatu e São Manuel, SP, respectivamente.

A análise dos dados foi feita num período de 36 anos (1971 a 2006), determinando-se: a temperatura média anual, a temperatura média do mês mais quente e do mês mais frio, a precipitação pluviométrica média anual, a precipitação pluviométrica máxima de verão e de inverno, e o mês de menor e maior precipitação pluviométrica. A caracterização das estações do verão e do inverno foi feita segundo o critério de Thornthwaite (1948), sendo considerado verão os três meses consecutivos mais quentes do ano (janeiro, fevereiro e março), e inverno como sendo os três meses consecutivos mais frios do ano (maio, junho e julho).

\subsection{Método de Köppen - algoritmo (Viana et al., 1997)}

Pensando em possibilitar posteriormente a confecção de um software, Viana et al. (1997) elaboraram um algoritmo de forma resumida que mostra ordenadamente os passos para a qualificação das diversas regiões, nos tipos e variedades climáticas que compõem a referida classificação.

Para a determinação da "primeira letra", considerou-se $\mathrm{P}=$ precipitação anual em cm e $\mathrm{T}=$ temperatura média anual em ${ }^{\circ} \mathrm{C}$. Após, considerou-se:

Condição (1): precipitação de inverno: $70 \%$ do total anual de precipitação ocorre durante os seis meses mais frios do ano; 
Condição (2): precipitação de verão: $70 \%$ do total anual de precipitação ocorre durante os seis meses mais quentes do ano;

Condição (3): quando não se aplica nenhuma das condições acima;

Se a condição (1) for verdadeira e se:

$\mathrm{P}>2 \mathrm{~T}$, então o clima é $\mathbf{A}, \mathbf{C}$ ou $\mathbf{D}$

$2 \mathrm{~T}<\mathrm{P}<\mathrm{T}$, então o clima é $\mathbf{B S}$ (estepe)

$\mathrm{P}<\mathrm{T}$, então é $\mathbf{B W}$ (deserto)

Se a condição (2) for verdadeira e se:

$\mathrm{P}>2(\mathrm{~T}+14)$, então o clima é $\mathbf{A}, \mathbf{C}$ ou $\mathbf{D}$

$(\mathrm{T}+14)<\mathrm{P}<2(\mathrm{~T}+14)$, então o clima é BS (estepe)

$\mathrm{P}<(\mathrm{T}+14)$, então o clima é BW (deserto)

Se a condição (3) for verdadeira e se:

$\mathrm{P}>2(\mathrm{~T}+7)$, então o clima é $\mathbf{A}, \mathbf{C}$ ou $\mathbf{D}$

$(\mathrm{T}+7)<\mathrm{P}<2(\mathrm{~T}+7)$, então o clima é BS (estepe)

$\mathrm{P}<(\mathrm{T}+7)$, então o clima é $\mathbf{B W}$ (deserto)

A partir dessas considerações, tem-se a "primeira letra" da classificação, que pode ser:

A - climas tropicais - temperatura do mês mais frio é superior a $18^{\circ} \mathrm{C}$;

B - climas secos - limites determinados em função da temperatura e precipitação;

$\mathbf{C}$ - climas temperados - temperatura do mês mais frio entre $18{ }^{\circ} \mathrm{C} \mathrm{e}-3^{\circ} \mathrm{C}$;

D - climas frios - temperatura do mês mais quente superior a $10^{\circ} \mathrm{C}$ e temperatura do mês mais frio inferior a $-3{ }^{\circ} \mathrm{C}$;

$\mathbf{E}$ - climas polares - temperatura do mês mais quente é inferior a $10^{\circ} \mathrm{C}$;

$\mathbf{F}$ - o mês mais quente é inferior a $0{ }^{\circ} \mathrm{C}$;

G - clima de montanha;

$\mathbf{H}$ - climas próprios de grandes altitudes.

Na determinação da "segunda letra", leva-se em conta os seguintes critérios:

A f - ausência de estação seca - o mês mais seco é maior que $6 \mathrm{~cm}$; A $\mathbf{m}$ - o mês mais seco é maior ou igual a (10 - P/25); $\mathbf{A} \mathbf{w}$ - quando não se aplicam as condições acima e a época mais seca ocorre no inverno;

B S - veja as condições (1), (2) e (3); B W - veja as condições (1), (2) e (3);

C, D s - quando as chuvas são de inverno, e a precipitação do mês mais chuvoso do inverno é igual ou maior que 3 vezes a precipitação do mês mais seco; $\mathbf{C}, \mathbf{D} \mathbf{w}$ - o mês mais chuvoso do verão é maior ou igual a 10 vezes o mês mais seco; $\mathbf{C}, \mathbf{D} \mathbf{f}$ - úmido, quando $\mathbf{s}$ e w não se aplicam;

$\mathbf{E} \mathbf{F}$ - todos os meses com temperatura média abaixo de $0{ }^{\circ} \mathrm{C} ; \mathbf{E} \mathbf{T}-\mathrm{o}$ mês mais quente tem temperatura entre $0{ }^{\circ} \mathrm{C}$ e $10{ }^{\circ} \mathrm{C} ; \mathbf{E} \mathbf{B}$ - de tundra ou neve perpétua;

$\mathrm{Na}$ "terceira letra", o critério a ser utilizado é a temperatura e deve-se considerar:

$\mathbf{a}$ - verão quente - o mês mais quente tem temperatura superior a $22{ }^{\circ} \mathrm{C}$;

b - verão moderadamente quente - temperatura do mês mais quente é inferior a $22{ }^{\circ} \mathrm{C}$ e pelo menos 4 meses tem temperaturas superiores a $10^{\circ} \mathrm{C}$;

c - verão breve e moderadamente frio - menos de 4 meses tem temperatura maior que $10^{\circ} \mathrm{C}$;

d - inverno muito frio - o mês mais frio tem temperatura inferior a $-38^{\circ} \mathrm{C}$;

Para regiões áridas (BS ou BW), usam-se os subscritos:

BSh' ou BWh' - muito quente - com temperatura média anual superior a $18{ }^{\circ} \mathrm{C}$ e mês mais quente com temperatura superior a $18^{\circ} \mathrm{C}$;

BSh ou BWh - quente - com temperatura média anual superior a $18{ }^{\circ} \mathrm{C}$ e mês mais quente com temperatura inferior a $18^{\circ} \mathrm{C}$; 
BSk ou BWk - frio - com temperatura média anual inferior a $18^{\circ} \mathrm{C}$ e mês mais quente com temperatura superior a $18^{\circ} \mathrm{C}$;

BSk' ou BWk' - muito frio - com temperatura média anual inferior a $18{ }^{\circ} \mathrm{C}$ e mês mais quente com temperatura inferior a $18^{\circ} \mathrm{C}$.

\subsection{Método de Thornthwaite (1948)}

O cálculo da evapotranspiração potencial foi feito segundo o método Thornthwaite (1948), e o cálculo do balanço hídrico climatológico (BHC) segundo o método de Thornthwaite \& Mather (1955), assumindo-se a capacidade de água disponível (CAD) do solo igual a $100 \mathrm{~mm}$, e segundo uma planilha eletrônica desenvolvida por Rolim et al. (1998).

Os cálculos dos índices de aridez, hídrico e de umidade foram processados conforme Thornthwaite (1948), segundo as expressões:

$$
I h=\frac{E X C}{E T P} 100
$$

Os municípios de Botucatu e de São Manuel tiveram a mesma classificação climática pelo método de Köppen, como sendo Cfa, clima temperado quente (mesotérmico) úmido, e a temperatura média do mês mais quente é superior a $22^{\circ} \mathrm{C}$. Pela classificação de Thornthwaite, houve uma pequena diferença em função do índice de umidade, caracterizando como $\mathbf{B}_{2} \mathbf{r B}{ }_{3}{ }_{3}$ ' (clima úmido com pequena deficiência hídrica - abril, julho e agosto, mesotérmico, com evapotranspiração potencial anual de $945,15 \mathrm{~mm}$ e concentração da evapotranspiração potencial no verão igual a 33\%) o município de Botucatu, e como $\mathbf{B}_{1} \mathbf{r} \mathbf{B}{ }_{3}{ }_{3} \mathbf{a}$ ' (clima úmido com pequena deficiência hídrica - abril, julho e agosto, mesotérmico, com evapotranspiração potencial anual de $994,21 \mathrm{~mm}$ e concentração da evapotranspiração potencial no verão igual a 33\%) o município de São Manuel.

$$
\begin{aligned}
& I a=\frac{D E F}{E T P} 100 \\
& I u=I h-0,6(I a)
\end{aligned}
$$

em que Ih é o índice hídrico, Ia o índice de aridez, Iu o índice de umidade, e EXC o excedente hídrico oriundo do balanço hídrico climatológico $(\mathrm{mm})$, DEF a deficiência hídrica oriunda do balanço hídrico climatológico $(\mathrm{mm})$, ETP a evapotranspiração de referência ou potencial $(\mathrm{mm})$.

As Tabelas: Tabela 1 (índice de umidade), Tabela 2 (índice de aridez e umidade), Tabela 3 (índice térmico) e Tabela 4 (ETPs de verão e anual) são apresentadas para permitir a classificação climática pelo método de Thornthwaite, as quais contém as chaves de classificação. 
Tabela 1. Chave inicial da classificação climática segundo Thornthwaite, baseados no índice de umidade (Ometto, 1981).

\begin{tabular}{|c|c|c|c|}
\hline Tipos Climáticos & \multicolumn{3}{|c|}{$\begin{array}{c}\text { Índice de Umidade (Iu) } \\
\text { Thornthwaite \& Mather (1955) }\end{array}$} \\
\hline $\mathbf{A}$ - Super-úmido & \multicolumn{3}{|c|}{$100 \leq \mathrm{Iu}$} \\
\hline $\mathbf{B}_{4}-$ Úmido & \multicolumn{3}{|c|}{$80 \leq \mathrm{Iu}<100$} \\
\hline $\mathbf{B}_{\mathbf{3}}$ - Úmido & \multicolumn{3}{|c|}{$60 \leq \mathrm{Iu}<80$} \\
\hline $\mathbf{B}_{2}-$ Úmido & \multicolumn{3}{|c|}{$40 \leq \mathrm{Iu}<60$} \\
\hline $\mathbf{B}_{1}-$ Úmido & \multicolumn{3}{|c|}{$20 \leq \mathrm{Iu}<40$} \\
\hline $\mathbf{C}_{2}-$ Sub-úmido & \multicolumn{3}{|c|}{$00 \leq \mathrm{Iu}<20$} \\
\hline $\mathbf{C}_{\mathbf{1}}-$ Sub-úmido seco & \multicolumn{3}{|c|}{$-33,3 \leq \mathrm{Iu}<00$} \\
\hline D - Semi-árido & \multicolumn{3}{|c|}{$-66,7 \leq \mathrm{Iu}<-33,3$} \\
\hline $\mathbf{E}$ - Árido & \multicolumn{3}{|c|}{$-100 \leq \mathrm{Iu}<-66,7$} \\
\hline \multicolumn{4}{|c|}{$\begin{array}{l}\text { Tabela 2. Segunda chave da classificação climática segundo Thornthwaite, baseados } \\
\text { índice de aridez e umidade (Ometto, 1981). }\end{array}$} \\
\hline $\begin{array}{c}\text { Climas úmidos } \\
\left(\mathrm{A}, \mathrm{B}_{4}, \mathrm{~B}_{3}, \mathrm{~B}_{2}, \mathrm{~B}_{1} \text { e } \mathrm{C}_{2}\right)\end{array}$ & $\begin{array}{l}\text { Índice de aridez } \\
\text { (Ia) }\end{array}$ & $\begin{array}{l}\text { Climas secos } \\
\left(C_{1}, D \text { e } E\right)\end{array}$ & $\begin{array}{l}\text { Índice de umidade } \\
\text { (Iu) }\end{array}$ \\
\hline $\begin{array}{c}\mathbf{r}-\text { pequena ou } \\
\text { nenhuma deficiência de } \\
\text { água }\end{array}$ & $0-16,7$ & $\begin{array}{c}\mathbf{d}-\text { pequeno ou } \\
\text { nenhum excesso de } \\
\text { água }\end{array}$ & $0-10$ \\
\hline $\begin{array}{c}\mathbf{s}-\text { moderada } \\
\text { deficiência no verão }\end{array}$ & $16,7-33,3$ & $\begin{array}{c}\mathbf{s}-\text { moderado } \\
\text { excesso de inverno }\end{array}$ & $10-20$ \\
\hline $\begin{array}{l}\mathbf{w}-\text { moderada } \\
\text { deficiência no inverno }\end{array}$ & $16,7-33,3$ & $\begin{array}{l}\mathbf{w}-\text { moderado } \\
\text { excesso de verão }\end{array}$ & $10-20$ \\
\hline $\begin{array}{c}\mathbf{s}_{2}-\text { grande deficiência } \\
\text { no verão }\end{array}$ & $>33,3$ & $\begin{array}{l}\mathbf{s}_{2}-\text { largo excesso de } \\
\text { inverno }\end{array}$ & 20 \\
\hline $\begin{array}{c}\mathbf{w}_{\mathbf{2}}-\text { grande deficiência } \\
\text { no inverno }\end{array}$ & $>33,3$ & $\begin{array}{l}\mathbf{w}_{\mathbf{2}}-\operatorname{largo} \text { excesso de } \\
\text { verão }\end{array}$ & 20 \\
\hline
\end{tabular}

Tabela 3. Terceira chave da classificação climática segundo Thornthwaite, baseados no índice térmico (It) (Ometto, 1981).

\section{Tipo climático}

A' - megatérmico

B' ${ }_{4}$ - mesotérmico

B' ${ }_{3}$ - mesotérmico

B' ${ }_{2}-$ mesotérmico

B' ${ }_{1}$ - mesotérmico

$\mathbf{C}^{\prime}{ }_{2}$ - microtérmico

$\mathbf{C}^{{ }^{1}}{ }_{1}$ - microtérmico

D' - tundra

E' - gelo perpétuo
Índice térmico (It)

(ETP anual)

$\geq 1.140$

$997-1.140$

$855-997$

$712-855$

$570-712$

$427-570$

$285-427$

$142-285$

$<142$ 
Tabela 4. Quarta chave da classificação climática segundo Thornthwaite, baseados na relação entre a ETP de verão e anual (Ometto, 1981).

\begin{tabular}{cc} 
Concentração da ETP no verão (\%) & Subtipo climático \\
\hline$<48 \%$ & $\mathbf{a}^{\prime}$ \\
$48-51,9$ & $\mathbf{b}^{\prime}{ }_{4}$ \\
$51,9-56,3$ & $\mathbf{b}^{\prime}$ \\
$56,3-61,6$ & $\mathbf{b}^{\prime}{ }_{2}$ \\
$61,6-68,0$ & $\mathbf{b}^{\prime}{ }_{1}$ \\
$68,0-76,3$ & $\mathbf{c}^{\prime}{ }_{2}$ \\
$76,3-88,0$ & $\mathbf{c}^{\prime}{ }_{1}$ \\
$>88,0$ & $\mathbf{d}^{\prime}$ \\
\hline
\end{tabular}

\section{RESULTADOS E DISCUSSÃO}

As Tabelas 5 e 6 apresentam o balanço hídrico climatológico (BHC) para os municípios de Botucatu e São Manuel, SP, para o período analisado (1971 a 2006).

Tabela 5. Balanço hídrico climatológico segundo Thornthwaite e Mather (1955), para o período de 1971 a 2006. Botucatu, SP, UNESP.

\begin{tabular}{|c|c|c|c|c|c|c|c|c|c|c|}
\hline MESES & $\begin{array}{c}\mathrm{T} \\
\left({ }^{\circ} \mathrm{C}\right) \\
\end{array}$ & $\begin{array}{c}P \\
(\mathrm{~mm})\end{array}$ & $\begin{array}{c}\text { ETP } \\
(\mathrm{mm})\end{array}$ & $\begin{array}{c}\text { P-ETP } \\
(\mathrm{mm}) \\
\end{array}$ & NEC & $\begin{array}{l}\text { ARM } \\
(\mathrm{mm})\end{array}$ & $\begin{array}{l}\text { ALT } \\
(\mathrm{mm})\end{array}$ & $\begin{array}{c}\text { ETR } \\
(\mathrm{mm})\end{array}$ & $\begin{array}{l}\text { DEF } \\
(\mathrm{mm})\end{array}$ & $\begin{array}{l}\text { EXC } \\
(\mathrm{mm})\end{array}$ \\
\hline JAN & 22,8 & 246,2 & 108,67 & 137,6 & 0,0 & 100,00 & 0,00 & 108,7 & 0,0 & 137,6 \\
\hline FEV & 23,1 & 199,1 & 101,86 & 97,3 & 0,0 & 100,00 & 0,00 & 101,9 & 0,0 & 97,3 \\
\hline MAR & 22,6 & 172,3 & 102,55 & 69,8 & 0,0 & 100,00 & 0,00 & 102,5 & 0,0 & 69,8 \\
\hline ABR & 21,0 & 66,8 & 79,56 & $-12,8$ & $-12,8$ & 88,01 & $-11,99$ & 78,8 & 0,8 & 0,0 \\
\hline MAI & 18,3 & 80,3 & 57,52 & 22,7 & 0,0 & 100,00 & 11,99 & 57,5 & 0,0 & 10,7 \\
\hline JUN & 17,2 & 55,8 & 46,22 & 9,5 & 0,0 & 100,00 & 0,00 & 46,2 & 0,0 & 9,5 \\
\hline JUL & 17,1 & 37,5 & 47,01 & $-9,5$ & $-9,5$ & 90,96 & $-9,04$ & 46,6 & 0,4 & 0,0 \\
\hline AGO & 18,5 & 36,1 & 57,62 & $-21,5$ & $-31,0$ & 73,36 & $-17,61$ & 53,7 & 3,9 & 0,0 \\
\hline SET & 19,1 & 87,6 & 63,43 & 24,1 & $-2,6$ & 97,47 & 24,12 & 63,4 & 0,0 & 0,0 \\
\hline OUT & 20,7 & 106,2 & 82,89 & 23,3 & 0,0 & 100,00 & 2,53 & 82,9 & 0,0 & 20,8 \\
\hline NOV & 21,6 & 139,1 & 93,04 & 46,0 & 0,0 & 100,00 & 0,00 & 93,0 & 0,0 & 46,0 \\
\hline DEZ & 22,2 & 201,4 & 104,78 & 96,6 & 0,0 & 100,00 & 0,00 & 104,8 & 0,0 & 96,6 \\
\hline ANUAL & $\overline{20,3}$ & $\overline{1.428,4}$ & 945,15 & 483,2 & - & 1.150 & 0,00 & $\overline{940,0}$ & 5,1 & 488,3 \\
\hline
\end{tabular}

$\mathrm{T}=$ Temperatura; $\mathrm{P}=$ Precipitação; ETP = Evapotranspiração potencial; NEG-AC = negativoacumulado; $\mathrm{ARM}=$ armazenamento; $\mathrm{ALT}=\mathrm{ARM}_{\text {atual }}-\mathrm{ARM}_{\text {anterior }} ; \mathrm{ETR}=$ Evapotranspiração real; DEF = Deficiência hídrica; EXC = excedente hídrico. 
Tabela 6. Balanço hídrico climatológico segundo Thornthwaite e Mather (1955), para o período de 1971 a 2006. São Manuel, SP, UNESP.

\begin{tabular}{|c|c|c|c|c|c|c|c|c|c|c|}
\hline MESES & $\begin{array}{c}\mathrm{T} \\
\left({ }^{\circ} \mathrm{C}\right) \\
\end{array}$ & $\begin{array}{c}\mathbf{P} \\
(\mathbf{m m})\end{array}$ & $\begin{array}{c}\text { ETP } \\
(\mathbf{m m})\end{array}$ & $\begin{array}{c}\text { P-ETP } \\
(\mathrm{mm})\end{array}$ & NEG-AC & $\begin{array}{l}\text { ARM } \\
(\mathbf{m m}) \\
\end{array}$ & $\begin{array}{c}\text { ALT } \\
(\mathbf{m m})\end{array}$ & $\begin{array}{l}\text { ETR } \\
(\mathbf{m m}) \\
\end{array}$ & $\begin{array}{c}\text { DEF } \\
(\mathrm{mm}) \\
\end{array}$ & $\begin{array}{l}\text { EXC } \\
(\mathrm{mm})\end{array}$ \\
\hline JAN & 23,4 & 219,4 & 113,35 & 106,0 & 0,0 & 100,00 & 0,00 & 113,4 & 0,0 & 106,0 \\
\hline FEV & 23,7 & 179,5 & 106,25 & 73,2 & 0,0 & 100,00 & 0,00 & 106,2 & 0,0 & 73,2 \\
\hline MAR & 23,4 & 165,6 & 109,20 & 56,3 & 0,0 & 100,00 & 0,00 & 109,2 & 0,0 & 56,3 \\
\hline ABR & 21,5 & 74,4 & 82,03 & $-7,6$ & $-7,6$ & 92,69 & $-7,31$ & 81,7 & 0,3 & 0,0 \\
\hline MAI & 18,9 & 80,3 & 59,16 & 21,1 & 0,0 & 100,00 & 7,31 & 59,2 & 0,0 & 13,8 \\
\hline JUN & 17,6 & 57,8 & 46,45 & 11,3 & 0,0 & 100,00 & 0,00 & 46,5 & 0,0 & 11,3 \\
\hline JUL & 17,6 & 33,0 & 47,94 & $-14,9$ & $-14,9$ & 86,13 & $-13,87$ & 46,9 & 1,1 & 0,0 \\
\hline AGO & 19,3 & 33,9 & 60,85 & $-26,9$ & $-41,9$ & 65,80 & $-20,33$ & 54,3 & 6,6 & 0,0 \\
\hline SET & 20,2 & 76,2 & 69,68 & 6,5 & $-32,4$ & 72,30 & 6,49 & 69,7 & 0,0 & 0,0 \\
\hline OUT & 21,7 & 120,6 & 89,68 & 30,9 & 0,0 & 100,00 & 27,70 & 89,7 & 0,0 & 3,2 \\
\hline NOV & 22,5 & 128,0 & 99,19 & 28,9 & 0,0 & 100,00 & 0,00 & 99,2 & 0,0 & 28,9 \\
\hline DEZ & 22,9 & 208,0 & 110,43 & 97,6 & 0,0 & 100,00 & 0,00 & 110,4 & 0,0 & 97,6 \\
\hline ANUAL & $\overline{21,0}$ & $1.376,7$ & $\overline{994,21}$ & 382,5 & - & 1.117 & 0,00 & $\overline{986,3}$ & 7,9 & 390,4 \\
\hline
\end{tabular}

\subsection{Método de Köppen}

Analisando os dados médios do período de 1971 a 2006 (36 anos), Tabela 5, para o município de Botucatu, SP, temos que:

Para a determinação da 'primeira letra', considerou-se a precipitação pluviométrica média anual $(\mathrm{P})$ em $\mathrm{cm}(142,84 \mathrm{~cm})$ e a temperatura média anual $(\mathrm{T}) \mathrm{em}{ }^{\circ} \mathrm{C}\left(20,3{ }^{\circ} \mathrm{C}\right)$. Como a maior ocorrência da precipitação é de verão, utilizou-se a condição (2), e com isto obteve-se: $142,84>68,60$, indicando que o clima pode ser A, C ou D. No entanto, tomando-se a temperatura média do mês mais frio $\left(\mathrm{Jul}=17,1^{\circ} \mathrm{C}\right)$, observou-se que ela está situada entre 18 e $-3{ }^{\circ} \mathrm{C}$, caracterizando como $\mathbf{C}$, clima temperado quente (mesotérmico).

Em seguida, para identificar a 'segunda letra' analisou-se as chuvas em cm, em função do mês mais chuvoso do verão (Jan $=24,62 \mathrm{~cm}$ ) e do mês mais seco (Ago $=3,61 \mathrm{~cm}$ ), obtendo-se $24,62 / 3,61=6,82$ vezes, ou seja, o mês mais chuvoso do verão não é maior ou igual a 10 vezes o mês mais seco, ficando com a letra $\mathbf{f}$ (úmido).

E finalmente, através da temperatura do mês mais quente e mais frio, foi identificada a 'terceira letra', obtendo-se a letra a, verão quente - o mês mais quente tem temperatura superior a $22{ }^{\circ} \mathrm{C}$, sendo que Botucatu apresenta uma temperatura de $23,1{ }^{\circ} \mathrm{C}$ no mês mais quente do ano (Fev).

Utilizando-se da mesma metodologia, foi também identificado o clima para o município de São Manuel, SP (Tabela 6).

$\mathrm{Na}$ 'primeira letra', considerando-se a precipitação pluviométrica média anual $(\mathrm{P}) \mathrm{em}$ $\mathrm{cm}(137,67 \mathrm{~cm})$ e a temperatura média anual $(\mathrm{T})$ em ${ }^{\circ} \mathrm{C}\left(21,0{ }^{\circ} \mathrm{C}\right)$. Como a maior ocorrência da precipitação é de verão, utilizou-se a condição (2), e com isto obteve-se: 137,67 > 70,00, indicando que o clima pode ser $\mathbf{A}, \mathbf{C}$ ou $\mathbf{D}$. No entanto, tomando-se a temperatura média do 
mês mais frio (Jun, Jul $=17,6^{\circ} \mathrm{C}$ ), observou-se que ela está situada entre 18 e $-3{ }^{\circ} \mathrm{C}$, caracterizando como $\mathbf{C}$, clima temperado quente (mesotérmico).

Em seguida, identificou-se a 'segunda letra' analisando-se as chuvas, em função do mês mais chuvoso do verão ( $\mathrm{Jan}=21,94 \mathrm{~cm})$ e do mês mais seco $(\mathrm{Jul}=3,30 \mathrm{~cm})$, obtendo-se $21,94 / 3,30=6,65$ vezes, ou seja, o mês mais chuvoso do verão não é maior ou igual a 10 vezes o mês mais seco, ficando com a letra $\mathbf{f}$ (úmido).

E finalmente, através da temperatura do mês mais quente e mais frio, foi identificada a 'terceira letra', obtendo-se a letra a, verão quente - o mês mais quente tem temperatura superior a $22{ }^{\circ} \mathrm{C}$, sendo que São Manuel apresenta uma temperatura de $23,7^{\circ} \mathrm{C}$ no mês mais quente do ano (Fev).

Portanto, no período analisado (1971 a 2006 - 36 anos) para os municípios de Botucatu e São Manuel, SP, o clima, segundo a metodologia de Köppen, foi caracterizado como sendo Cfa, clima temperado quente (mesotérmico) úmido, e a temperatura média do mês mais quente é superior a $22^{\circ} \mathrm{C}$.

\subsection{Método de Thornthwaite (1948)}

A partir dos cálculos dos índices de aridez, hídrico e de umidade, e também das Tabelas: Tabela 1 (índice de umidade), Tabela 2 (índice de aridez e umidade), Tabela 3 (índice térmico), Tabela 4 (ETPs de verão e anual), Tabela 5(BHC Botucatu) e Tabela 6(BHC de São Manuel), foi possível classificar o clima dos municípios de Botucatu e de São Manuel, SP.

O BHC para Botucatu no período de 1971-2006 (Tabela 5) apresentou uma evapotranspiração potencial (ETP) de $945,15 \mathrm{~mm}$, uma evapotranspiração real (ETR) de 940,00 mm, uma deficiência hídrica (DEF) de 5,10 mm, um excesso hídrico (EXC) de 488,30 mm, um índice hídrico (Ih) igual a 51,66, um índice de aridez (Ia) igual a 0,54, um índice de umidade (Iu) igual a 51,34, e uma relação da evapotranspiração potencial de verão pela evapotranspiração potencial anual (ETPv / ETP) igual a 33\%.

Utilizando-se da 'chave inicial', em função do Iu igual a 51,34, obteve-se a letra $\mathbf{B}_{\mathbf{2}}$ (Tabela 1), caracterizado como úmido. Em seguida, através da 'segunda chave', e baseado no Ia igual a 0,54, obteve-se a letra $\mathbf{r}$ (Tabela 2), apresentando pequena ou nenhuma deficiência de água. Usando-se a 'terceira chave', em função do It, ou seja, a ETP anual de 945,15 mm, obteve-se a letra B' 3 (Tabela 3) que indica ser mesotérmico. Finalmente, através da 'quarta chave', em função da relação da evapotranspiração de verão (ETPv) igual a 313,08 mm (meses de janeiro, fevereiro e março) pela evapotranspiração anual (ETP) 945,15 mm, obtevese a letra a' (Tabela 4) que indica a percentagem da concentração da ETP no verão (33\%).

O BHC para São Manuel no período de 1971-2006 (Tabela 6) apresenta uma ETP de 994,21 mm, uma ETR de 986,30 mm, uma DEF de 7,90 mm, um EXC de 390,40 mm, um $\mathrm{Ih}$ de 39,27, um Ia de 0,80, um Iu de 38,79, e uma relação ETPv / ETP igual a 33\%.

Através da 'chave inicial', em função do Iu igual a 38,79, obteve-se a letra $\mathbf{B}_{1}$ (Tabela 1), caracterizado como úmido. Em seguida, com a 'segunda chave', e baseado no Ia igual a 0,80 , obteve-se a letra $\mathbf{r}$ (Tabela 2), apresentando pequena ou nenhuma deficiência de água. Usando-se a 'terceira chave', em função do It, ou seja, a ETP anual de 944,21 mm, obteve-se a letra $\mathbf{B}_{3}{ }_{3}$ (Tabela 3 ) que indica ser mesotérmico. Finalmente, através da 'quarta chave', em função da relação da ETPv igual a 328,70 mm (meses de janeiro, fevereiro e março) pela ETP anual de $944,21 \mathrm{~mm}$, obteve-se a letra a' (Tabela 4) que indica a percentagem da concentração da ETP no verão (33\%).

Para o município de Botucatu, no período analisado (1971 a 2006 - 36 anos), o clima segundo a metodologia de Thornthwaite foi caracterizado como sendo $\mathbf{B}_{2} \mathbf{r} \mathbf{B}{ }_{3} \mathbf{a}^{\prime}$, clima úmido 
com pequena deficiência hídrica (nos meses de abril, julho e agosto), mesotérmico, com ETP anual de $945,15 \mathrm{~mm}$ e concentração da evapotranspiração potencial no verão $(\mathrm{ETPV}=$ meses mais quentes) igual a $33 \%$.

Para o município de São Manuel, o clima foi caracterizado como sendo $\mathbf{B}_{1} \mathbf{r} \mathbf{B}{ }_{3} \mathbf{a}$ ', clima úmido com pequena deficiência hídrica (nos meses de abril, julho e agosto), mesotérmico, com uma ETP anual de 994,21 mm e concentração da ETPv (meses mais quentes) igual a $33 \%$.

\section{CONCLUSÕES}

A temperatura média anual apresenta-se maior no município de São Manuel, tendo como consequência uma maior evapotranspiração potencial. Em Botucatu, ocorre uma maior precipitação pluviométrica anual, o que está associada às condições orográficas locais;

Nas duas localidades, ocorrem deficiências hídricas nos meses de abril, julho e agosto, e o período chuvoso se concentra nos meses de primavera-verão, com índices hídricos relativamente elevados;

Os municípios de Botucatu e de São Manuel apresentaram a mesma classificação climática pelo método de Köppen, como sendo Cfa. Pela classificação de Thornthwaite, o município de Botucatu ficou caracterizando como $\mathbf{B}_{2} \mathbf{r} \mathbf{B}{ }_{3} \mathbf{a}$ ' e o de São Manuel como $\mathbf{B}_{1} \mathbf{r B}{ }_{3} \mathbf{a}^{\prime}$;

As duas classificações utilizadas mostraram semelhanças na caracterização do clima dos municípios de Botucatu e São Manuel, mas, no entanto, a classificação climática de Köppen perde em detalhes, pois não diferencia os tipos climáticos, enquanto que a de Thornthwaite, além de levar em conta a temperatura, precipitação e evapotranspiração, apresenta com detalhe o período de déficit e excedente hídrico anual de uma localidade.

\section{REFERÊNCIAS BIBLIOGRÁFICAS}

DANTAS, A.A.A., CARVAlHO, L.G., FERREIRA, E. Classificação e tendências em Lavras, MG. Ciência e Agrotecnologia, Lavras, v.31, n.6, p.1862-1866, 2007.

DEFFUnE, G., DELAVALENTINA, D.J., GALVANI, E., AVANCINI, M. Classificação climática e índices de aridez para Maringá-PR, de 1976/1992. Boletim de Geografia, Maringá, Ano 12, Junho, 1994.

FIGUEIREDO, J.C., SUGAHARA, S. Classificação climática e o aspecto climatológico da cidade de Bauru. In: CONGRESSO BRASILEIRO DE AGROMETEOROLOGIA, 10., 1997, Piracicaba, SP. Anais... Piracicaba: Sociedade Brasileira de Agrometeorologia, 1997. p.377379.

JURCA, J. Classificações climáticas: variações temporo-espaciais e suas aplicações nos livros didáticos e como subsídio ao zoneamento agroclimático. 2005. 100f. Dissertação (Mestrado em Geografia) - Faculdade de Ciências e Tecnologia, Universidade Estadual Paulista, Presidente Prudente, 2005.

NOGUEIRA, F.C.B., LIMA, F.A.M. Classificação climática de Thornthwaite dos municípios de 
Pacoti e Guaramiranga, Ceará. Ciência Agronômica, Fortaleza, v.1/2, n.20, p.175-183, 1989.

OMETTO, J.C. Bioclimatologia vegetal. São Paulo: Agronômica Ceres, 1981. 440p.

ROLIM, G.S., SENTELHAS, P.C., BARBIERI, V. Planilhas do ambiente EXCELTM para os cálculos de balanços hídricos: normal, sequencial, de cultura e de produtividade real e potencial. Revista Brasileira de Agrometeorologia, Santa Maria, v.6, n.1, p.133-137, 1998.

SANTANA, J.A.S., SANTANA JR., J.A.S., SOUTO, J.S., MACEDO, A.B. Balanço hídrico e classificação climática de Thornthwaite da sstação Ecológica do Seridó, Serra Negra do Norte, RN. Brasil Florestal, n.80, Agosto, 2004.

THORNTHWAITE, C.W. An approach toward a rational classification of climate. Geography Review, v.38, p.55-94, 1948.

THORNTHWAITE, C.W., MATHER, J.R. The water balance. Publications in Climatology. New Jersey: Drexel Institute of Technology, 104p. 1955.

VIANA, T.V.A., BASTOS, E.A., ALVES, D.R.B., FOLEGATTI, M.V. Algoritmo da classificação climática de Köppen. In: CONGRESSO BRASILEIRO DE AGROMETEOROLOGIA, 10, 1997, Piracicaba, SP. Anais... Piracicaba: Sociedade Brasileira de Agrometeorologia, 1997. p.255-9.

VIANELLO, R.L., ALVES, A.R. Meteorologia básica e aplicações. Viçosa, UFV: Imprensa Universitária, 2000. 449p. 